\title{
Hibridismo contemporâneo: questões vertiginosas entre as artes visuais e a publicidade \& propaganda*
}

\section{Hibridity contemporary: issues dizzying between the visual arts and publicity \& advertising}

Pedro Lacerda ${ }^{1}$ Flor Marlene E. Lopes ${ }^{2}$
Recebido em: 05/05/2015.

Aprovado em: 19/05/2015.

1 Pedro Lacerda Graduado em Publicidade \& Propaganda-UniCEUB, graduando em Licenciatura em Artes Plásticas Ida-UnB. Cursou Fotografia Avançada em Madrid/Espanha. Membro do Grupo de Pesquisas em "Narrativas fotográficas interativo-visual", da Profa. Dra. Denise Camargo.

2 Flor Marlene E. Lopes é Doutora em Semiótica pela Universidade de São Paulo USP, Professora pesquisadora do UniCEUB. Coordenadora da Pós-Graduação na Faculdade de Artes Dulcina de Moraes.

\section{Resumo}

Já não é de hoje que muitos pensadores, críticos e historiadores tratam com seriedade os rumos que a arte vem tomando nas últimas décadas. Seu desligamento com a história evolucionista do homem a permitiu ser livre, tendo, agora, seu próprio caminho. Em sua independência, entretanto, a arte não caminha só: encontra no pop, no mercado e na publicidade vários aliados que fazem jus aos períodos em que vivemos, $\mathrm{o}$ contemporâneo. As discussões aqui propostas buscam esclarecer rotas de um caminho altamente vertiginoso entre as artes visuais e a publicidade \& propaganda, onde encontrar respostas, hoje, provavelmente não seja a melhor solução. E sim, talvez, aprender a moldar estas várias relações que, muitas vezes escorregadias, podem levar a arte à um caminho sem volta - se é que não já a levou..

Palavras-chave: Arte. Publicidade \& Propaganda. Contemporâneo. Indústria Cultural. Pós-modernidade. Pop Art.

\begin{abstract}
It is not new that reaseachers, critics and historians treat in serious way the art direction in the last decades. Its disconnection with the man's evolutionist history allowed it to be free, having now, its own way. In its independence, however, the art is not going alone: finds in the pop, the market and the publicity a lot of allies that represent well the period we live on, the contemporary. The discussions here proposed intend to make clear the routes of a really-vertiginous way between visual arts and publicity \& advertising, where find answers, nowadays, is probably not the best solution. But maybe, learn how to shape those different relationships that can take art to a way with no return - if they did not take it yet.
\end{abstract}

Keywords: Art. Publicity \& Advertising. Contemporary. Industry. Post-modern. Pop-Art. 


\section{Introdução}

Pensar e refletir as práticas e valores derivados das Artes Visuais e da Publicidade \& Propaganda é uma tarefa mais do que essencial para quem deseja entender do que as duas têm a propor. Compreender a dualidade de conceitos, querer se aventurar na vertiginosa discussão entre uma e outra, e entender que nem sempre há imediatas respostas para todas as atuais questões é uma boa forma de iniciar essa tarefa - uma vez que com o advento da contemporaneidade, seus rumos parecem traçar rotas à um sincretismo altamente instigante e questionador.

As Artes Visuais, até então "pura", singela e incansavelmente repleta de boa fama e caráter, vê em seu destino um alarmante sinal: a perda de seu valor. Ao partir de um princípio em que "tudo é arte", pode-se observar - e não é de hoje - que objetos, ícones e práticas têm carregado cada dia mais o status artístico.

Do outro lado, temos a publicidade, tão sedutora, atrativa, mentirosa e repleta de desejos por atenção. Vê neste "advento da perda de valores artísticos" a oportunidade perfeita para ser entrelaçada aos méritos (agora não mais) filosóficos, transformadores e inteligentes da arte. Ao mesmo tempo, prostitui o que já conhece de técnica e teoria sem nenhum e qualquer pudor, buscando no fetiche a arma principal para alcançar seu principal objetivo: vender.

Logo, entender que este recente diálogo composto por espaços tão adversos - mas ao mesmo tempo, hoje, tão aparentemente unidos - não possui contornos definidos, é o principal agente motivador deste artigo, que se coloca no intuito de discuti-los, compreende-los e, principalmente, contextualizá-los no atual período em que vivemos.

\section{Narrativas e mutações: arte rumo aos desdo- bramentos dos séculos XIX e XX}

Sendo executada no chamado "novo mundo", por volta do final do século XIX e início do XX, onde muitas mudanças foram vivenciadas em pouco tempo, a arte também percebia uma transformação: o chamado período "moderno" começava a aflorar. Havia uma necessidade em se fazer uma "nova arte" para um "novo mundo", mesmo que em caráter experimental, através da busca a respostas e questionamentos que dissessem respeito so- bre a natureza da arte, da experiência humana e da autocrítica.

Assuntos que até então nas artes eram velados e camuflados, passaram a ser percebidos de outra maneira: sendo o assunto principal do trabalho. Tanto o realismo, impressionismo, naturalismo, quanto outros períodos, dissimulavam os meios, usando a arte para ocultar a própria arte. Tudo o que já foi assunto a ser posto em "coxias" ou bastidores da arte, no Modernismo pôde-se ver o mesmo "em cima dos palcos". A atenção principal estava no modo como o assunto é tratado, e não mais no que é retratado.

Mesmo por vezes indo de encontro a visões arcaicas, o Modernismo, com seus individuais objetivos, jamais pretendeu exaltar uma ruptura com o passado. Diferentemente do contemporâneo - a ser tratado mais à frente - o Modernismo se caracteriza, também, por ser um momento de transição onde estabelece uma linearidade histórica com o que já foi produzido, e abre portas para uma maior liberdade artística culminante da década de 60 até os dias de hoje.

Uma outra questão a respeito da Arte Moderna é sobre a quebra conceitual que gira em torno da contraditória relação entre belo e útil - talvez o primeiro passo para a futura "arte funcional", resultante na Publicidade \& Propaganda de nossos dias. No trecho de "O mundo como vontade e representação", de Arthur Schopenhauer, subtende-se haver um grande vácuo entre utilidade e beleza. Segundo o Filósofo, "não poder ter utilidade nem ser lucrativo é uma característica do trabalho do gênio; é o seu título de nobreza" (SCHOPENHAUER apud DANTO, 2006, p. 90). Contudo, tal premissa foi rejeitada desde o pré-Moderno, onde buscava-se unir e justificar cada vez mais a funcionalidade de algo com seu cunho estético, sempre atrelado ao mercado de ornamentação artística e arquitetural.

Fazendo o oposto do que a Pop Art futuramente viria trazer - do mercado às artes - a Art Nouveau foi responsável por levar as artes ao mercado, prevalecendo-se de objetos comuns do cotidiano e da arquitetura com o intuito de atribuí-los um cunho artístico e um traço particular. Ocorria a formação de um princípio de arte funcional entre os artistas já que estes "se tornaram autoconscientes acerca do estilo e começaram a experimentar e a desencadear novos movimentos" (GOMBRICH, 1985, p. 442).

Controversos e "modernos" debates sempre foram 
imprescindíveis em torno da Arte Moderna, mas provavelmente nada repercutiu tanto quanto um transgressor acontecimento ainda do início do século XX - talvez o mais importante do movimento para esta discussão aqui proposta. O ano de 1917 tinha reservado para a história da arte um início de inúmeros "delitos" que colocavam em questão a tradicional crítica estética de arte. O ready made "Fountain", de Marcel Duchamp, ao ser exposto numa exposição da Sociedade de Artistas Independentes, pode ser considerado como símbolo icônico das novas obras de arte que seriam produzidas - e até hoje são onde "a beleza na verdade não poderia constituir nenhum atributo definidor da arte" (DANTO, 2006, p. 92). Seria essa a grande razão para Danto (2006) vir a denominar que a Arte tinha chegado ao seu fim.

Embora o termo "fim" tenha sido imposto pelo autor de maneira um tanto quanto alarmante para o que realmente queria dizer, sua mensagem não deixa de ser coerente. Nicolas Bourriaud (2009) veio a definir de maneira mais objetiva que não se tratava de um "fim da arte". Segundo o autor "não há 'fim da história' nem 'fim da arte' possíveis, porque a partida sempre é retomada em função do contexto, [...] em função dos jogadores e do sistema que eles constroem ou criticam” (BOURRIAUD, 2009, p. 25).

De qualquer forma o "divórcio entre a estética e atividade artística é confirmado" através do urinol, como já anunciava Cauquelin (2010, p. 90). Duchamp fazia uma crítica afirmativa à não-estética, alegando que qualquer objeto ao ser exposto - e aí está um importante ato, responsável, agora, por toda a reclassificação e denominação do que é arte ou não é arte - se tornaria uma obra, já que é o ato da mostra, da "exibição", que consagra e eleva a peça ao patamar de arte, e não mais a própria obra por si só.

Ao promover a não-estética clássica, Duchamp, e a maioria dos "Dadas", buscavam (re) viver um renascimento onde a primeira guerra mundial traria à eles uma nova excitação. Para Stephen Farthing (2010) “os dadaístas achavam que a arte havia traído a humanidade e era essa postura essencialmente antiartística que tornava o dadaísmo tão dinâmico”. Contudo, Cauquelin deixa claro que tal posicionamento não seria uma "antítese” ou uma oposição quanto à arte, mas sim uma "deslocação de domínio, [onde] a arte já não é uma questão de conteúdo (formas, cores, visões, interpretações [...]) mas de forma que contém, ou invólucro" (CAUQUELIN, 2010, p. 63) o que acaba por ser atrelado à famosa frase de Marshall McLuhan, onde "o meio é a mensagem.
O Modernismo - ou a Era dos Manifestos - se viu perdida tendo em vista a impossibilidade de julgar apenas em termos visuais o que seria uma "obra de arte" e o que não seria uma "obra de arte", além de ter sentido a necessidade de buscar uma nova estética baseada na ideologia e não mais no material.

Sendo livre, não havendo crítica nem comentário, a obra definitivamente não caminharia mais ao encontro da estética, já que esta é quem "constrói uma área de validade para as obras, impondo regras, exigências, critérios" (CAUQUELIN, 2010, p. 107). A arte, enfim, passa a caminhar um rumo onde rotas vertiginosas sentirão a necessidade de criação de uma "nova" estética, definitivamente próxima do mercado, da comunicação e do pop. $\mathrm{O}$ mundo estava em mudança e os artistas da época apenas retratavam o que estava em sua volta. Tal comportamento começa a ser percebido pela sociedade pós $2^{\text {a }}$ guerra, que acaba por gerar ao mundo um inédito cenário onde a indústria rege e abala diversas áreas do conhecimento, entre elas, as artes visuais.

\section{Popart, arte contemporânea e indústria cul- tural: um sincretismo não só poético entre arte, mercado e comunicação - uma introdu- ção ao diálogo entre arte e publicidade}

“Ganhar dinheiro é arte, trabalhar é arte e fazer bons negócios é a melhor das artes”. Talvez esta frase de Andy Warhol seja a definição mais abrangente do que a arte viria propor ao cenário social da segunda metade do século XX. Sendo reconhecida por muitos como um movimento nem um pouco coerente, a Pop Art tinha particularidades e princípios individuais que variavam de artista para artista, e que estavam dispostos a girar em torno do problema de qual "o lugar do artista e do seu produto - a obra de arte [...] - no moderno mundo de consumo e da comunicação de massa” (FARTHING, 2010, p. 487). Ao integrar a arte à sociedade de consumo, seria difícil haver um contínuo desenvolvimento das avant-gardes proposto no Modernismo, já que estas vinham sempre acompanhadas de uma forte crítica da sociedade comercial através da denúncia ou recusa de valores capitalistas. E a própria Pop caminha bem próxima ao capitalismo...

A falta de credibilidade à assuntos sociais entre os artistas pop se estendeu à transgressão teórica onde re- 
jeitavam, naturalmente, fórmulas e teses, principalmente filosóficas. Warhol, ao expor uma caixa de sabão em pó, a Brillo Box, contraria filósofos que sempre afirmaram ser possível fazer a distinção entre arte e realidade utilizando-se puramente de termos visuais, e ainda levanta questões a respeito do porquê algo não ser uma obra de arte. As heranças modernistas geraram à Arte Pop o ato em apontar um objeto e denominá-lo arte, como Duchamp o fazia. Sob a visão do artista dadaísta, o que foi dito é "Esse urinol é uma obra de arte". Já na geração pop, a questão de Warhol seria "Por que todos os outros urinóis não são obras de arte?".

Focados em atar os laços entre arte e mundo laços, estes, que na sua grande maioria sempre estiveram distantes - os artistas viram nos elementos e objetos usuais um valor moral a ser usado como tema, afim de democratizar a vivência artística. "Em lugar de rejeitarem os produtos deploráveis do mundo moderno, comercial e industrial, [...] voltaram-se com excitação para aquilo que os mais exigentes de nós consideram como [...] lixo." (SALOMON apud BATTCOCK, 2002, p. 230). São as cores vivas, os sentimentos efêmeros, os produtos fabricados de forma generalizada, celebridades, cartazes, televisão, lanchonetes, máquinas de jogo, dentre outros inúmeros elementos. Mesmo que venha a denunciar em alguns casos de forma involuntária, a principal perversão da Pop Art baseia-se em celebrar algo. O que na verdade estava acontecendo era uma ressignificação de signos já conhecidos.

Andy Warhol, considerado por Anne Cauquelin (2010) o grande representante da arte contemporânea, expunha o mercado como crítica, mas também o utilizava a seu favor sem qualquer pudor, e, diferentemente de Duchamp, que restringia ao "lugar" o ato consagrador responsável por denominar uma obra de arte, este usava a repetição em série - assim como campanhas publicitárias hoje o fazem, utilizando-se de vários meios para se auto propagar, afim de se estabelecer na comunicação como um todo. O museu de Warhol é a sociedade, é a comunicação. E se a obra não vier acompanhada de sua assinatura, melhor ainda, já que a intenção é propagar a obra e não a "marca" Warhol. Sobre o novo "espaço de arte", Cauquelin diz que foi passado de um "lugar determinado, marcado por uma etiqueta 'arte', para o conjunto de um circuito que vai ocupar por completo" (CAUQUELIN, 2010, p. 75). Em suma, é o que Warhol dizia sobre reprodutibilidade técnica ao se referir às suas serigrafias, a clássica técnica alojada ao efeito de linha de produção, e considerada por muitos críticos como um kitsch de preço elevado, ao refletir sobre a "suposta singularidade da obra de arte em um mundo de reprodução e comunicação de massa" (FARTHING, 2010, p. 489). Contudo, se Warhol induzia à reprodução em série de suas serigrafias, não haveria nelas a notoriedade, discutida por Walter Benjamin em "A obra de arte na era da sua reprodutibilidade técnica", em carregar consigo mesma a pureza e autenticidade, já que o tão consagrado "aqui e agora" da obra não existe. $\mathrm{E}$ isso seria, para Benjamin, o que faria todas as obras de arte provindas da reprodutibilidade não nos levarem ao êxito maior, às volúpias ao se enxergar uma pintura, por exemplo.

Mesmo não visando propagar suas obras através de seu nome, Andy Warhol se viu transformar-se em uma "marca". Parecia que todas as suas obras, quer fossem fotografias, serigrafias, pinturas, xilogravuras, filmes, etc., faziam parte de um só conjunto chamado Warhol - tornando seu nome uma própria obra - exatamente como acontece no atual sistema de comunicação, ao identificar o nome de um produto atrelado à marca: denominamos Bombril como qualquer lã de aço ou Gilette como qualquer lâmina de barbear. É eliminada a "separação que existe entre o nome que designa um autor singular e a assinatura que promove este nome como signo que vale por ele. Nome, assinatura e obra confundem-se." (CAUQUELIN, 2010, p. 79). Se equivale a dizer que hoje em dia qualquer pessoa pode comprar um "Citroën Picasso", ou uma "Havaiana Romero Britto". O signo Picasso (o pintor), por exemplo, é esvaziado de significado, e a Citroën o apropria levando-o ao encontro dos princípios da marca. A contemporaneidade traz aos artistas o status de ícone - não para suas obras, mas para si mesmos.

Assim como Danto, Gompertz (2013) trata dos novos valores propostos pelo contemporâneo ao explicitar desavenças entre os dois períodos vigentes durante o século XX. Aos que acreditam que essa transgressão poética só foi exalada com o advento pós-modernista, o autor desmente: o Moderno, por si só, já era uma rejeição à tradição - já o pós-modernismo não rejeitaria nada. Paralelamente, Cauquelin (2006) vai de encontro à essa opinião ao expor que a Arte Moderna, por sugerir e ser guiada por uma libertação contra valores academicistas, não se referia a renunciar tudo o que "já aconteceu". Segundo a autora, o Moderno seria muito uma "constatação da impotência do sistema para gerir o domínio da 
arte e dos artistas do que uma recusa dos valores certificados e definidos pelo sistema" (p. 24). Já para definir arte contemporânea - principalmente a dos anos 90 em diante, Nicolas Bourriaud designa o início da história da arte como a relação homem-divindade, a arte moderna como homem-objeto, e, por fim, o contemporâneo como homem-homem. "O artista concentra-se cada vez mais decididamente nas relações que seu trabalho irá criar em seu público ou na invenção de modelos de socialidade" (BOURRIAUD, 2009, p. 40) - o que vai de encontro às ideias de Alan Salomon, onde os "novos artistas" da década 60 teriam seus interesses baseados muito mais em torno das experiências individuais e na relação homem-ambiente. Como já explicitado, a arte contemporânea é (sempre) mutável. Não existe "verdade". E sim "verdades".

O que até então pode nos parecer um utópico cenário para os artistas, em que a bela liberdade é capaz de reger as condutas artísticas utilizando-se de várias maneiras e linguagens para se produzir, na verdade se apresenta de maneira bem difícil de lidar já que, uma vez sendo transgressora, a arte contemporânea carrega consigo uma grande descrença não só por parte do público, mas também pelos seus próprios praticantes.

O que se pode observar, então, é um comportamento muito próximo do que é feito atualmente por qualquer um de nós - principalmente ao nos referirmos e aproximarmos obras de arte do ambiente da comunicação (publicidade) - quando, na verdade, estamos diante de mais um "problema" na história. Como os artistas pop já proclamavam, "esta exigência de pureza, esta recusa do comércio e da arte comercial desapareceram com o abandono da estética" (CAUQUELIN, 2010, p. 80). Logo, na contemporaneidade, a obra de arte cada vez mais se assemelha à, e é tratada como, um produto de massa. De forma sucinta, é a real vivência de um dos princípios provindos da Pop Art: acreditar que a alta e baixa cultura são uma coisa só.

Agora não só em termos poéticos, a arte definitivamente se aproxima do sistema comunicacional e mercadológico afim de caminhar em conjunto com a sociedade em meio ao cenário da indústria cultural, como é assim chamada pelos filósofos e sociólogos Adorno e Horkheimer. Segundo Silva (2002) o período pós-guerra veio reger à sociedade as leis de mercado, sendo assim "quem conseguisse acompanhar esse ritmo [...] conseguiria sobreviver; aquele que não conseguisse [...] ficava a mercê dos dias e do tempo, isto é, jogado à margem da sociedade". E a arte, claro, caminhou em conjunto. Cauquelin contribui à discussão ao comentar que, especificamente para o período contemporâneo, o sistema de comunicação gerou uma espécie de dependência às artes no sentido de lhe proporcionar um apoio, uma promoção da imagem do que ela realmente é. Sendo assim a "realidade da arte contemporânea constrói-se fora das qualidades inerentes à obra, [e sim] na imagem que suscita nos circuitos de comunicação" (p. 56). Ou seja, pode-se subentender que a arte estaria para a comunicação, assim como um cliente está para uma agência de publicidade. A comunicação teria o papel de agenciar a arte na pós-modernidade, já que ela só, por si própria, já não é capaz de se auto-sustentar.

A discussão parece mais se relacionar ao clássico vínculo entre um protagonista e antagonista, respectivamente: arte e mercado (ou vice-versa). São inúmeros os teóricos que fazem dessa discussão tema para suas pesquisas. Ao se referirem ao atual mercado de arte, onde uma vez comercializada uma obra, esta passaria a adquirir primeiramente um valor completamente comercial, já que o dinheiro cobriria quase que por completo toda a aura de sua natureza pictórica/poética. A obra, então, deixa de ser "de arte" e passa a ser "de consumo". Sua noção de importância e valor sentimental se tornam diretamente proporcionais ao seu valor monetário. E quem conduz os trilhos agora é o próprio artista, que, por fim, se torna "artista de negócios", ou melhor dizendo, um publicitário de sua própria criação. Bourriaud já comentava que uma obra de arte, mesmo não tendo uma função utilitária a priori, se entrega ao universo de trocas e vendas, ou seja, do comércio, da comunicação:

Todas as mercadorias têm um valor, isto é, uma substância comum que permite sua troca; essa substância, segundo Marx, é a 'quantidade de trabalho abstrato' utilizada para produzir tal mercadoria. Ela é representada por uma quantia de dinheiro, que é o 'equivalente geral abstrato' de todas as mercadorias entre si. Quanto à arte, e Marx foi o primeiro a dizê-lo, ela representava a 'mercadoria absoluta', visto que era a própria imagem do valor. (BOURRIAUD, 2009, p. 59)

Pode-se constatar, então, uma grande instabilidade no mundo da arte. Para os artistas então, seria seguir o mercado ou a própria arte? Ficar para trás ou andar conforme o trilho? Se vender ou ser fiel à própria produção? Abaixar o preço do quadro ou manter o original? Fazer "dois por um", ou impor um preço único condizente à contemplação do ato criador? O que se discute aqui, po- 
rém, é que, se então a obra de arte tem um valor monetário, se há um regime para isso, e se a lei de mercado e comunicação adentram por completo à arte, o quão caótico seria se o produto de massa se apropriasse da arte? Em outros termos, esta pesquisa se concentra no seguinte questionamento: se a obra de arte já se assemelhou à um produto de consumo, quais rumos seriam tomados se um produto de consumo se assemelhasse à uma obra de arte?

\section{A nova (nova) arte: o produto de massa como obra - publicidade \& propaganda}

Vale ressaltar que, embora este artigo tem a preocupação em tratar o "produto de massa" como a Publicidade \& Propaganda, é notável assumir que tal premissa se estende, e muito, a todo o universo da arte comercial. Seja a indústria musical de nossos dias, a moda, o design, dentre qualquer outra área correlativa. Lady Gaga, por exemplo, cujo último álbum tem o nome $A R T P O P$, vai ao encontro desta afirmativa ao aclamar " $A$ cultura pop estava na arte. Agora a arte está na cultura pop, em mim!"

Enfim, seria a Publicidade então uma forma de arte. São inúmeros os argumentos que defendem com louvor os dois diferentes posicionamentos. Ao adentrarmos à resposta afirmativa da questão, pode-se dizer que “sim, publicidade é arte! Afinal, uma peça publicitária é fruto de uma bela combinação estética de um profissional que estudou para isso. Um Diretor de Arte que leva em conta princípios como cor, forma e linha; um profissional que estudou fundamentos de linguagem visual, estudou artistas plásticos, obras renomadas, e que tem uma proximidade com o desenho, a fotografia ou outra linguagem mais propriamente artística. Um profissional que visa propagar uma ideologia, mesmo que esta seja relacionada ao consumo, à venda”.

Tais justificativas se apresentam tão convincentes quanto à sua oposição, ao proclamarmos que "não, claro que Publicidade não é arte! Dificilmente uma peça publicitária apresenta algo realmente novo. Tudo não passa de um 'mexido' de referências com um gostinho de 'já vi isso alguma vez'. Não há progressões históricas e desenvolvimentos técnicos significativos que possam ser capazes de fomentar a afirmativa que publicidade é só mais uma linguagem visual como a pintura, fotografia ou escultura. Afinal, uma peça publicitária carrega consigo um caráter altamente não-autoral exclusivo de uma só pessoa, já que surgem, no decorrer de seu desenvolvimento, 'outros autores' que apontam defeitos, falhas, corrigem elementos, e onde até pessoas que não estudaram Publicidade ou não se atentam à nenhum princípio estético ordenam o Diretor de Arte (o "artista" em forma de marionete) a fazer as temidas alterações em uma peça - visando o princípio básico de toda e qualquer artimanha publicitária: vender.

Afirmar que arte pode ser propaganda é completamente admissível, aceitável e válido diante do que aqui já foi exposto, como já afirmado neste artigo. Contudo, declarar seu oposto, que propaganda é arte, é uma questão ainda muito complexa a ser analisada, e que dificilmente algum dia terá uma resposta tão universal no que diz respeito à propaganda como um todo. Afirmar que Andy Warhol ou Roy Lichtenstein tomavam posse de peças publicitárias ou artes gráficas afim de nomeá-las "arte", ou que ainda as obras de Toulouse-Lautrec, na Art Nouveau, eram produzidas nos moldes de um cartaz, não é suficiente para dizer que a propaganda simplesmente "ê" arte gratuitamente, mas sim talvez que ela "se torne" arte através da (e somente pela) mão de um artista.

Estar entre defensores ou acusadores da publicidade como arte: esse é o cenário completamente partidarista que se encontra todo e qualquer interessado em entender as delimitações e relações destas duas áreas. Observa-se então que, de um lado, os diretores de arte em agências se vangloriam ao dizer que estão sim fazendo arte ao criar suas peças publicitárias, assim como utilizam os mesmos princípios visuais de um artista para criar suas peças (cor, imagem, harmonia, equilíbrio, contraste, peso, simetria), que fazem proveito da alarmante premissa "tudo é arte" provindo do cínico reconhecimento da arte contemporânea, e que transportam a arte arcaica de museu para a velocidade de transmissão de mensagens do homem pós-moderno (ou seja, a publicidade). Por outro ângulo, os artistas - principalmente os mais arcaicos - estão cada vez mais interessados em afastar suas obras do mercantil reconhecimento "efêmero" e "fingido" que a publicidade tem, mas ao mesmo tempo fazem parte de um circuito proporcionado pela própria arte contemporânea onde há a necessidade de se renovarem e estarem ativos permanentemente "sob pena de desaparecer no movimento perpétuo de denominação que mantém a rede [de arte] de vento e popa" como diz Anne Cauquelin (2006, p. 53), e ainda querem tomar para si o grande benefício que a publicidade (de si mesmos) pode vir a proporcioná-los: ganhar dinheiro. Sendo assim, vemos fotos de Salvador 
Dalí, Andy Warhol e Jeff Koons tão difundidas quanto (ou até mais) que suas obras.

Publicitários e artistas contemporâneos se encontram, agora, dividindo experiências, benefícios, vivências e formas de produção bem próximas. Jeff Koons (1955), por exemplo, tem uma verdadeira "fábrica" para produzir suas tão conhecidas esculturas, que funciona de maneira bem próxima à relação de um diretor de criação e um diretor de arte: "legiões de assistentes produzem esculturas e pinturas segundo suas especificações, enquanto ele supervisiona as operações como o diretor de criação numa agência de publicidade" (GOMPERTZ, 2013, p. 405). Assim como Barbara Kruger (1945) imita os métodos em que são construídos cartazes publicitários afim de questionar as práticas comerciais do mundo da arte, em suas obras carregadas de tons emergenciais, como também nos conta Gompertz (2013). Ou ainda como Bourriaud (2009) trata, a arte atual se baseia no signo da não-disponibilidade, já que muitas vezes se apresenta de forma efêmera e instantânea, como as performances e happenings que, salvo os registros fotográficos ou em filmagens, acontecem "naquele momento e agora" - se aproximando cada vez mais do princípio ágil e imediato da comunicação de nossos dias. As duas áreas passam a ser tão próximas que seus conceitos quase se confundem: "Há... elementos que são mais híbridos do que 'puros', contaminados em vez de 'limpos', 'ambíguos' em vez de 'articulados', 'perversos', bem como 'interessantes"' (DANTO, 2006, p. 14). Estaria este trecho se referindo à arte contemporânea ou à publicidade \& propaganda?

[A publicidade] é obra de artistas, quer dizer, gente originalmente nascida para alta realização nas artes plásticas ou na literatura, mas que preferiu (sem que desmereçam casos de vocação específica) ganhar dinheiro. Bem, não são mais artistas, pensando no que se entende por arte. Contudo, independentemente de juízos de valor, eles participam inegavelmente do núcleo de nossa civilização, da pretensão feérica de nossos tempos, que esconde, em efeitos eletrônicos fascinantes, a "decadência contemporânea" (no sentido que nos fala Michael Harrington, estudioso da realidade sociocultural). (BARRETO, 2006, p. 6)

Pode-se subentender então que peças publicitárias nada mais são do que simulações das próprias artes visuais. Jean Baudrillard (1991, p. 13) define muito bem essa relação ao dizer que a "simulação se opõe à representação. Esta parte [...] do princípio de equivalência, parte da negação radical do signo como valor". Além disso, a impressão que se tem é que aconteceu uma espécie de troca entre a arte e a publicidade; as duas passam a incorporar do melhor que cada uma pode tirar da outra. Já que a arte contemporânea se tornou mais exigente ao público - exigente na questão de se tornar compreensível dentro de seu contexto e por quem a aprecia -, a publicidade, que caminha passos mais largos à velocidade de nossa sociedade, se apresenta no patamar do efêmero através da imediatez de suas mensagens, não necessitando haver por parte do receptor qualquer reflexão, pensamento crítico ou algo do gênero. Apenas é entregue o "produto final" já mastigado, e carregado de inúmeras referências que, novamente segundo Adorno e Horkheimer (1947), não é exigido trabalho algum diante de quem o recebe. Apenas exige-se sua consumação - e como toda coisa mastigada, esta já não tem mais gosto, justamente afim de ser consumida de novo, e de novo, e de novo...

Mas afinal, por que publicitários se encontram nesse marasmo de produzir mentiras pós mentiras, e apresentarem cenários utópicos em meio à personagens (im) perfeitos e sorridentes, em vez de fazerem uso de maneira benéfica do poder monstruoso que têm em mãos? Tal questão, muito levantada por Oliviero Toscani (2003), evidencia o motivo da publicidade não ser reconhecida como arte. Banal do jeito que se apresenta, e fácil de ser digerida e consumida pela massa, é muito mais prático e óbvio que as grandes empresas façam seus investimentos em campanhas que induzem o imediato consumo do serviço ou produto, do que gerar outras espécies de conteúdo ou temáticas para campanhas, principalmente as sociais - já que toda e qualquer peça publicitária tem que falar a íngua de seu público. E a língua da massa é a ordinária, a vulgar e a fácil. $\mathrm{O}$ autor, ao defender um de seus anúncios produzidos que trazia a Aids como tema central, relata que muitos não conseguiam compreender que ele "pudesse utilizar a impressionante capacidade de exposição da publicidade para revelar essa tragédia, quando ainda ninguém tinha tido a coragem de mostrar os doentes" (TOSCANI, 2003, p. 25). Ainda sobre a questão, o autor relata que "os publicitários não cumprem a sua função: comunicar. Carecem de ousadia e de senso moral. Não refletem sobre o papel social, público, e educativo da empresa que lhes confia um orçamento" (TOSCANI, 2003, p. 25), e sim preferem buscar o reconhecimento de ser uma arte, sem se dar ao trabalho.

Uma peça publicitária que se coloque em discussão, que questione sua verdade e que não só cumpra seu papel de vender: essa sim seria verdadeiramente a publicidade-arte. Assim como a Pop buscou a aproximação 
entre arte e realidade, a publicidade deveria, por sua vez, utilizar-se do mesmo princípio, que por sinal é o utilizado pelo fotógrafo italiano. Suas peças publicitárias (ou obras de arte?) foram expostas nos museus de arte contemporânea mais renomados na cidade do México e São Paulo. O filósofo Régis Debray (1940) clareava essa relação tão próxima, agora, entre publicidade e arte ao tratar de como as fotos de Toscani terem chegado à museus mais facilmente em comparação à outras fotografias ou peças: "A publicidade clássica tinha setenta anos de atraso em relação à vanguarda, a reality pub enfim alcança o ready made. Suprimir o fosso entre a arte e a vida, entre as imagens e as coisas, é objetivo de todos nós depois de Marcel Duchamp" (DEBRAY apud TOSCANI, 2003, p. 96).

Pode-se observar que, nas mãos de todo e qualquer artista, ao estar produzindo verdadeiramente arte - mesmo que nos moldes da publicidade, ela sempre será arte. Roy Linchtestein, um dos maiores nomes da $P o p$, já citado aqui, ao se referir às peças de Toscani para a Benetton, em 1994, ressaltava tal ideia ao aclamar que "essa gente é vanguarda em matéria de arte publicitária" (LINCHTESTEIN apud TOSCANI, 2003, p. 139). Não só a arte, como a publicidade - finalmente - também passa a observar possibilidades de transformação. E seu novo processo de ressignificação e produção talvez puxe a arte para caminhar de mãos dadas.

Cabe, então, a todo publicitário entender a matriz de seu papel e a responsabilidade ao dizer que se está fielmente produzindo arte em publicidade. Oliviero Toscani, por exemplo, soube muito bem tratar da troca de valores e da discussão a respeito de si mesma com suas "publicidades artísticas". A maior troca a ser feita não seria de dinheiro ou poder entre o cliente consumidor e a marca, e sim de valores, como Bourriaud deixava claro ao dizer que, embora uma obra de arte assuma a etiqueta "preço" - assim como as fotos de Toscani também o fazem involuntariamente - a primeira relação de trocas que está sendo feita é a de sentidos, de valores e de práticas. Afinal, ser artista, além de ser uma condição, é uma profissão. E talvez o ateliê de alguns artistas, hoje, seja a agência de publicidade ou um estúdio de fotografia publicitária.

Como o fotógrafo italiano nos demonstra, o hibridismo contemporâneo, enfim, começa a acontecer e a surtir efeitos tanto entre publicitários, tanto entre artistas. E este - híbrido - pode suportar qualquer coisa....

\section{Considerações finais}

Mas afinal, por que a publicidade gostaria de vir a ser arte? Seria pela busca aos atributos filosóficos, transformadores, inteligentes, fiéis e inovadores que ela sempre teve em toda a história? De toda forma, o que se percebe é uma certa expansão de intenções por parte da publicidade, de tal modo que sempre quer ser mais do que realmente é. Justo ela que busca passar para o consumidor uma fantasiosa e inatingível realidade. Entretanto, não é preciso ir muito longe para se entender o porquê a publicidade não ser facilmente reconhecida como arte. Afinal, fica difícil para publicitários defender como um comercial de tênis ou um anúncio literalmente ordinário de lojas de eletrodomésticos pode ser equiparada à uma obra. E, agora exercendo a visão de se pensar a partir da arte, como defender também que obras contemporâneas tão absurdas, diferentes, e tão próximas da maneira de se produzir publicidade simplesmente "são" arte? Somente pela tal licença poética? Tal resposta não se delimita à uma única e simples afirmativa, mas sim acaba por englobar um amplo cenário onde arte contemporânea, comunicação, sociedade e tantas outras áreas de atuação e pesquisa, estão atuando como protagonistas - afinal, a arte de nossos dias tende a trabalhar cada vez mais com temas transversais. Como diria o artista Allan Kaprow (1927-2006), nem toda arte, para ser arte, precisa necessariamente se parecer com arte. Enquanto isso, os agentes atuantes, frutos desta discussão, continuam trabalhando, produzindo, baseando-se na falta de preocupação em querer anunciar uma posição quanto aos limites deste sincretismo. Afinal, como diz Danto (2006), a ausência de direção é o traço que define o novo período.

\section{Referências}

BARRETO, R. M. Agência de propaganda e as engrenagens da história. São Paulo: Summus, 2006.

BATTCOCK, G. A nova arte. 2. ed. São Paulo: Perspectiva, 2002.

BAUDRILLARD, J. Simulacros e simulação. Lisboa: Relógio D’Água, 1991.

BENJAMIN, W. A obra de arte na era de sua reprodutibilidade técnica. Disponível em: <http://www.mariosantiago.net/Textos\%20em\%20PDF/A \%20obra\%20de $\% 20$ arte $\% 20$ na $\% 20$ era $\% 20$ da $\% 20$ sua $\% 20$ reprodutibilidade\%20t\%C3\%A9cnica.pdf>. Acesso em: 11 maio 2014. 
BOURRIAUD, N. Estética relacional. São Paulo: Martins, 2009.

CAUQUELIN, A. Arte contemporânea. São Paulo: Europa-America, 2010.

CESAR, N. Direção de arte em propaganda. São Paulo: Futura, 2000.

DANTO, A. C. Após o fim da arte: a arte contemporânea e os limites da história. São Paulo: Odysseus, 2006.

FARTHING, S. Tudo sobre arte. Rio de Janeiro: Sextante, 2011.

FERREIRA, G.; MELLO, C. C. Clement Greenberg e o debate crítico. Rio de Janeiro: Jorge Zahar, 1997.

GOMBRICH, E. H. A história da arte. 4. ed. Rio de Janeiro: Zahar, 1985.
GOMPERTZ, W. Isso é arte? : 150 anos de arte moderna do impressionismo até hoje. Rio de Janeiro: Zahar, 2013.

LITTLE, S. Ismos: para entender a arte. São Paulo: Globo, 2010 .

PROENÇA, G. História da arte. 17. ed. São Paulo: Ática, 2008.

SILVA, D. R. Adorno e a indústria cultural. Disponível em: <http://www.urutagua.uem.br//04fil_silva.htm >. Acesso em: 11 maio 2014.

TOSCANI, O. A publicidade é um cadáver que nos sorri. 5. ed. Rio de Janeiro: Ediouro, 2003. 